\section{Para além do lógos: a peste de Atenas na obra de Tucídides}

\begin{abstract}
A peste de Atenas tornou-se célebre mais por sua descrição empreendida por Tucídides do que por seu reflexo nos destinos da cidade. O peso simbólico do evento tem seus significados radicados na crise política que Atenas enfrentou, graças tanto ao assédio dos lacedemônios quanto ao questionamento acerca do desempenho de suas instituições. A crise institucional tem manifestações plurais, mas está sobretudo calcada na etiologia que advém da oscilação axiológica do princípio do medèn ágan, do "nada em excesso". Tal princípio afinava-se com os postulados da medicina hipocrática, que, na obra de Tucídides, é utilizada tanto na afirmação desse princípio como valor, quanto no que se chamou, na dissertação, de "método hipocrático". A dissertação, portanto, procura assinalar essas duas vias de influência da medicina sobre o olhar que Tucídides lança sobre a pólis ateniense.
\end{abstract}

A história da guerra, presente direta ou indiretamente na obra de muitos autores clássicos, foi tematizada por Tucídides, em uma obra que recebeu o nome de $A$ guerra do Peloponeso. Esta longa guerra (durou de cerca de 431 a 404 a.C) logrou envolver quase todos os povos gregos, que, no mínimo, sentiram seus efeitos. No relato de Tucídides, nota-se como, naquele momento, havia uma grande moção na maioria dos povos gregos, o que o historiador ateniense eleva a uma situação sem precedentes.

Tucídides, consoante sua tarefa de historiador, constrói a história da guerra, uma vez que ele próprio participou dela, na condição de estratego. Em sua obra nota-se uma riqueza e uma minuciosidade incomuns em descrições análogas e coetâneas, principalmente no livro II. Tal detalhamento acurado afere mais autoridade ao relato e mais soli- dez à construção de uma verdade histórica que imperou por muitos séculos no imaginário grego e na cultura ocidental.

A guerra tem como motor a disputa da hegemonia territorial entre as duas póleis envolvidas, e a origem da refrega remete ao descontentamento dos espartanos com a atuação de Atenas na administração do espólio da guerra contra os persas.

A invasão da Ática é marcada por grandes destruições, os peloponésios devastaram primeiro aqueles campos, obrigando a população, sob ordens de Péricles, a refugiarse no centro urbano. Ao mesmo tempo em que a cidade era destruída por terra, os atenienses com seus navios assediavam o litoral do Peloponeso. Por um tempo, os atenienses tiveram relativos sucessos; porém, com uma segunda invasão da Ática e com a desapropriação da zona rural, a cidade começou a enfrentar uma grave crise: a peste. Relembrando uma imagem terrífica de Tucídides, a cidade definhava por dentro e por fora (éndon kaì éxo), pois enquanto os atenienses caíam por terra devido à guerra, a peste dizimava a população no interior da cidade.

Nesta dissertação procurou-se perceber o lugar e a importância que o pensamento médico do século $\mathrm{V}$ a.C. tem na historiografia de Tucídides, tomando como corpus a descrição da peste de Atenas no segundo livro d' A guerra do Peloponeso. O historiador, ao descrever a peste, o faz fundamentado em sua própria observação, mas dentro de um modelo hipocrático de percepção da verdade. Sua primeira questão é procurar a origem do mal, para o qual é reivindicada a Etiópia - que, no imaginário grego, era o ponto mais distante no mundo como atestam, a partir da Ilíada, vários documentos. A doença teria entrado, então, pela região portuária de Atenas, Pireus, de onde se difunde por toda a pólis (chóra e ásty). Tucídides descreve o lugar, o período e os sintomas da doença. 
Percebe-se, então, a ineficácia da medicina e da religião, pois os médicos não conheciam a natureza da peste, mesmo porque não houvera nenhum conhecimento desta doença anteriormente, e as preces e apelos aos oráculos não surtiam efeito, já que não se atribuía à doença nenhuma origem divina, como a que aparece no primeiro canto da Ilíada ou como a peste descrita em Édipo Rei, que, apesar de ter uma relação claramente simbólica com a vida política, mantém sua causa divina consoante o mito do qual é uso e expressão.

Nota-se, então, que a peste não é uma inovação do historiador, já que a literatura grega possuía outros casos conhecidos e importantes como a Ilíada e Édipo Rei. Porém a descrição de Tucídides se destaca em relação a essas duas, pelo fato de não incluir Apolo como causa nem um oráculo como mediador. O historiador ao mencionar o oráculo o faz de forma irônica, oferecendo, no entanto, uma chave de leitura para o próprio texto de sua lavra. Sua conclusão sobre a interpretação vacilante das palavras do oráculo sentencia: "os homens constroem a memória de acordo com suas vicissitudes". Eis o que faz Tucídides, e eis como li sua obra.

Na descrição da peste, o autor sugere uma contrapartida social para esse mal, e o escopo dessa dissertação é estudar como a peste confronta dois pólos de um modelo teórico. Tucídides, que utiliza o corpo humano para falar do corpo social da pólis, encontra na peste o momento em que ambos os corpos se unem no ambiente da doença, o momento em que se diluem as idéias de público e privado. $\mathrm{O}$ Corpus hippocraticum servirá de contraponto teórico para notar-se que idéias de corpo, doença e saúde teriam servido a Tucídides. Além disso, ao relatar a guerra, o historiador ateniense faz uma descrição dos homens e do mundo, apoiando-se no método hipocrático. Ele descreve as atitudes e ações do homem no mundo, fundamentado no princípio de que há uma natureza humana perene, o que também o aproxima das linhas gerais (e rarefeitas) do pensamento hipocrático.

O método empírico detectado por Cornford no Corpus hippocraticum está presen- te na narrativa da guerra, posto que é através das observações sistemáticas de casos que o historiador procura compreender as causas da peste (e mesmo da guerra), e é através do conhecimento das causas que ele procurará supor alguma solução política ou alguma profilaxia social. É, mais uma vez, o pensamento hipocrático agindo na formação da idéia de interdependência entre diagnóstico e prognóstico.

Tucídides, através do discurso de Péricles, procura fazer uma interpretação política dos acontecimentos, pois o tempo em que a cidade sofreu com a peste, a política também sofreu males, ou seja, interpreta a guerra como um grande mal físico.

O mal físico e o mal social se confundem quando a peste é descrita. Enquanto a cidade padece com a peste, o desequilíbrio - os aspectos que se podem notar no que Tucídides escolheu chamar de anomía - toma conta do corpo social. Tal mecanismo de utilização de modelo pode ser percebido claramente quando o historiador conta que as pessoas relacionam a segunda chegada dos peloponésios à ocorrência da peste e, conseqüentemente, acusam Péricles pela guerra e pela doença, o que o leva a convocar uma assembléia a fim de ressaltar a importância de um todo unificado em detrimento do desmembramento (Tuc., II, 60), onde se nota mais uma vez a influência do método hipocrático.

A individualização ou a singularização coloca em risco o regime político, o sistema democrático poderia, assim, fragilizar-se diante do perigo monárquico que Atenas tanto teme. O discurso acerca do ideal unificador parece fazer ecoar os princípios norteadores do tratado Da natureza do homem.

$\mathrm{O}$ arconte convence o povo ateniense a continuar na guerra, no entanto, a peste acaba por contribuiu consideravelmente para as derrotas de Atenas, já que a doença durou dois anos e voltou assolar a cidade por uma segunda vez (Tuc., III, 87), embora Tucídides seja categórico ao afirmar que a peste nunca saiu de Atenas. De fato, para livrar-se de um mal é necessário eliminar sua causa. Enquanto houver anomía haverá 
loimós. O historiador chega a comparar o governante a um médico, pois ambos são responsáveis por manter o equilíbrio entre as partes do todo.

O fato de o corpo ter saúde com a homeostase e de isso estar de acordo com um ideal político, o do medèn ágan (nada excessivamente), faz com que os princípios da medicina como téchne sirvam para livrar a cidade de seus males, e os princípios da medicina como campo do conhecimento, com fronteiras definidas, sirvam para uma leitura da pólis.

Tucídides, como foi dito, utiliza o método hipocrático para descrever a peste e falar sobre a cidade, e, estando a peste no ponto liminar entre individual e o coletivo, ela se presta a ser, para o historiador, a ponte que propicia pensar na nósos da cidade e em suas causas sociais, como sugere o autor, por exemplo, na passagem II, 54 de sua obra.

Não seria difícil, a partir desse excerto supor uma etiologia política para o episódio da peste. E assim, consoante aos autores que postulam a compreensão do corpo como modelo para entender a cidade. No historiador, tal perspectiva tende a contribuir para a reflexão acerca do momento em que o corpo encontra-se com a cidade.

Cabe salientar, ainda, que a peste de Atenas é abordada na dissertação a partir da contribuição do texto de Tucídides para sua inscrição na história de Atenas e, por conseguinte, na história da civilização ocidental. Não se discute a factualidade da peste, mas sim o discurso que edificou sua imagem social na cultura grega.

Trata-se, no entanto, de um trabalho a partir do texto, que não prescinde da tradução deste, uma vez que é no texto original que se procuraram os elementos da argumentação que foi desenvolvida no trabalho. Justamente por repensar o texto original a partir da abordagem proposta, não foi possível prescindir de uma proposta de tradução que contemplasse as observações oriundas dos dados textuais examinados.

Coube à tradução a tarefa de tentar passar ao vernáculo o texto que criou um dos mais relevantes fatos da história do Ocidente, que, apesar (e por causa) da contestação de sua dimensão factual, constituiu em uma das peças mais interessantes e importantes da retórica historiográfica, que ensinou à história a construir e ao homem político a pensar.

Finalmente, cabe acrescentar que o desenvolvimento do tema da dissertação objetiva oferecer a dimensão simbólica da construção discursiva do episódio da peste de Atenas e a contribuição da literatura médica para essa construção.

\section{Andréa Coelho Farias Draeger \\ Dissertação de mestrado em Letras Clássicas, 2004 Faculdade de Letras da Universidade Federal do Rio de Janeiro Av. Jequitibá, 2151 Cidade Universitária 21941-590 Rio de Janeiro - RJ acoelhof@uol.com.br}

\section{A profissão de fisioterapia em Minas Gerais: uma história oral de suas raízes}

Com base em estudo qualitativo e utilizando a história oral e a análise de documentos, procurou-se identificar as raízes da fisioterapia em Minas Gerais, a fim de discutir o processo de profissionalização e o desenvolvimento da identidade do fisioterapeuta neste estado. $\mathrm{O}$ foco do estudo foi dirigido principalmente a Belo Horizonte, no período compreendido entre 1950 e 1980 . O referencial teórico utilizado foi a sociologia das profissões e teve como guia os cinco passos de profissionalização descritos por Wilensky (1964). São eles: a necessidade de a ocupação tornar-se de dedicação exclusiva, o estabelecimento de procedimentos de instrução e seleção, a formação de uma associação profissional, a regulamentação da profissão e a adoção do código de ética. $\mathrm{Na}$ pesquisa de campo, utilizaram-se entrevistas do tipo semi-estruturada para colher depoimentos de pessoas consideradas chave, mediante amostragem em série. $\mathrm{O}$ méto- 
do escolhido foi a análise de conteúdo, sendo adotadas categorias como forma de orientação. Avalia-se que o processo de profissionalização da fisioterapia em Minas Gerais é marcado pela hegemonia médica na saúde e que a indefinição das atribuições e competências foram os fatores que motivaram os conflitos internos e externos. Conclui-se que, para a afirmação efetiva da fisioterapia como profissão, torna-se necessária a delimitação das especificidades do seu saber e do seu fazer (teoria e prática), identificando o papel do fisioterapeuta na equipe multidisciplinar de saúde.

\section{Maria do Carmo Nascimento} Dissertação de mestrado em ciências da reabilitação, 2004 Escola de Educação Física, Fisioterapia e Terapia Ocupacional Universidade Federal de Minas Gerais Av. Antônio Carlos, 6.627

31270-901 Belo Horizonte - MG Brasil carminha_sa@terra.com.br

\section{Das Cordilheiras dos Andes à Isla de Cuba, passando pelo Brasil: os congressos médicos latino-americanos e brasileiros (1888-1929)}

No final do século XIX e início do século $X X$ ocorreram diversas reuniões científicas no continente americano, entre elas os Congressos Médicos Latino-Americanos, sediados no Chile (1901), Argentina (1904), Uruguai (1907), Brasil (1909), Peru (1913) e Cuba (1922) e os Congressos Brasileiros de Medicina e Cirurgia (1888-1929), tema con- templado nesta tese. A abordagem seguida foi a de considerar estas reuniões científicas como momentos importantes para a consolidação do conhecimento e da profissão médica no continente latino-americano, levando em consideração o contexto sócio-cultural das relações internacionais daquele período.

Como um trabalho inserido na área de história social das ciências, enfatizou-se a dinâmica de organização dos eventos citados, priorizando os principais debates ocorridos e decisões tomadas no que se refere às intervenções médicas no meio social e à organização profissional do campo médico. Ao mesmo tempo, analisaram-se as polêmicas noções de progresso, civilização e nação, como parte integrante do processo de constituição do saber médico na região.

Destacou-se também a dimensão das Exposições Internacionais de Higiene que integravam as atividades dos congressos médicos latinos, concebendo-as não somente como exibição do 'estado da arte' do conhecimento médico e da tecnologia sanitária, mas também como estratégias de fortalecimento do profissional da medicina.

Desta forma, a intenção maior desta tese foi contribuir com a história das ciências na América Latina, a partir do reconhecimento de que houve intercâmbios científicos na região - incluindo aí o Brasil - mais efetivos do que convencionalmente aparece na historiografia.

Marta de Almeida

Tese de doutoramento em história social, 2004 Faculdade de Filosofia, Ciências Humanas da Universidade de São Paulo, Rua José Álvares Maciel, 391/41 05539-080 São Paulo - SP Brasil marta@mast.br 